\title{
DEVELOPMENT OF pNH4-ISFETS MICROSENSORS FOR WATER ANALYSIS
}

\author{
I. Humenyuk, B. Torbiéro, S. Assié-Souleille, R. Colin, X. Dollat, \\ B. Franc, A. Martinez, $\underline{\text { P. Temple-Boyer }}$
}

LAAS-CNRS, 7 av. du Colonel Roche, 31077 Toulouse Cedex 4, France

\begin{abstract}
Front-side connected, N-channel, normally-off, $\mathrm{SiO}_{2} / \mathrm{Si}_{3} \mathrm{~N}_{4}$ chemical field effect transistor (ChemFET) microsensors have been fabricated using a standard P-well silicon technology. These ChemFETs microsensors were adapted to ammonium ion detection thanks to photosensitive polysiloxane (PSX) polymer containing nonactine as an ionophore. The ammonium-sensitive membrane has been deposited either manually by micropipette, either by spin coating and patterned using photolithography technique. Both processes have been studied and compared through the ammonium ion determination. The manually deposed layers have been characterised by thickness non-reproducibility. Therefore, spin-coated layers have good reproducibility, but their thickness of $30 \mu \mathrm{m}$ has been responsible for an increase of the ISFET threshold voltage and a decrease of its bias current. Nevertheless, in both cases, good sensitivities have been shown on the $[1-5] \mathrm{pNH}_{4}$ range even if saturation phenomena have been evidenced for the lowest concentrations. These pNH4-ISFETs microsensors are developed for the monitoring of environmental pollution and more precisely for ground water analysis.
\end{abstract}

Keywords: ChemFET sensor, $\mathrm{pNH}_{4}{ }^{+}$ion detection, water analysis 


\section{Introduction}

The water analysis techniques require the development of smart chemical sensors with the following characteristics: good sensitivity and selectivity, mass fabrication, low cost, low power and ease of use. In this context, the chemical field effect transistor (ChemFET) as a solid-state sensor is fully compatible with silicon technologies and provides the required characteristics. Its potentiometric measurement principle is well adapted to the detection of ions in aqueous solutions [1]. As a well-known device derived from microelectronics, its electric behaviour, characterisation techniques and measurement interfaces have been thoroughly studied. Thus, standard front-side connected ion sensitive field effect transistors (FSC-ISFETs) have been realised and the detection of ions in aqueous solutions has been successfully fulfilled thanks to many polymer-based ion-sensitive layers: Poly vinyl chloride (PVC) [2], polyHEMA/siloprene [3], polyurethane/acrylate [4], polysiloxane (PSX) [5, 6, 7].

To go further and reach industrial development, the ISFET microsensor has to be fully adapted to the water analysis using different packaging techniques. The design of the back-side connected (BSC) ISFET has been proposed to do that [8]. It eliminates the necessity of the chip hand-made packaging and is fully compatible with the flow analysis concept [9]. However, its technological process is more complex, and therefore more expensive and less reliable from an industrial point of view, than the FSC-ISFET one. Thus, in order to reach a global optimisation of the ISFET microsensors fabrication, the standard front-side connected structure has to be adapted to the developed flow-through cell devices presented in figures 1 and 2.

This paper deals with such development of front-side connected FSC-ChemFETs microsensors for water analysis applications. It presents the improvement of the realisation of ISFET microsensors, taking into account the deposition of polysiloxane-based ion-sensitive layers. Demonstration is finally performed through the detection of the $\mathrm{NH}_{4}{ }^{+}$ion in aqueous solutions.

\section{Experimental}


Front-side connected, N-channel, normally off, ion-sensitive field effect transistors (ISFETs) were built on $<100>$-oriented, N-type $(500 \Omega . \mathrm{cm})$, silicon substrates using standard P-well technology. A 30nm thermally grown $\mathrm{SiO}_{2}$ layer and a 80nm LPCVD $\mathrm{Si}_{3} \mathrm{~N}_{4}$ layer deposited on top formed the $\mathrm{pH}$-sensitive gate structure. Taking into account the $\mathrm{P}$-well and the dielectric gate technological processes and characteristics, the pH-ISFET microsensor was optimised in order to have a threshold voltage $\mathrm{V}_{\mathrm{t}}$ about 0.7 volt [3]. The $5 \times 5 \mathrm{~mm}^{2}$ silicon chip also includes a reference metal oxide/nitride $\mathrm{SiO}_{2}(30 \mathrm{~nm}) / \mathrm{Si}_{3} \mathrm{~N}_{4}(80 \mathrm{~nm})$ silicon field effect transistor (ReMOS) used for electric test as well as for future drift and/or temperature compensations (figure 3).

The $\mathrm{pH}-\mathrm{ISFETs}$ were adapted to the $\mathrm{NH}_{4}{ }^{+}$ion detection using polysiloxane-based ionsensitive layers. The polysiloxane (PSX) copolymer RMS-033 containing methacrylate groups was purchased from ABCR. The PSX layers were deposited on the $\mathrm{pH}$-sensitive gate either manually by micropipette, either by spin-coating and photolithography techniques. All the chemical reagents required by these two technological processes were purchased from SigmaAldrich.

The manually deposed ion-sensitive PSX membranes were realised according to a technological process developed by the Warsaw University of Technology [10]. It contained $100 \mathrm{mg}$ of polysiloxane, $1 \mathrm{mg}$ of 2,2-dimethoxy-2-phenylacetophenone (DMPA) photoinitiator, $2 \mathrm{mg}$ of nonactine acting as ammonium-sensitive ionophore, $1.5 \mathrm{mg}$ of potassium tetrakis[3,5bis(trifluoromethyl)phenyl] borate (KTFBP) used as lipophilic salt and $1 \mathrm{ml}$ of tetrahydrofuran (THF) used as solvent. After the THF evaporation at $80^{\circ} \mathrm{C}$ (duration: 6 hours) and the 3-(methacryloxy)propyl trimethoxysilane (MPTS) / toluene silanisation step at $80^{\circ} \mathrm{C}$ to promote adherence, the membrane solution (approximately $10 \mu \mathrm{L}$ ) were deposited on the $\mathrm{SiO}_{2} / \mathrm{Si}_{3} \mathrm{~N}_{4}$ gate. Then, the polymerized PSX layers (thickness around 10 microns) were obtained by exposure to ultraviolet (UV) illumination (duration: $200 \mathrm{~s}$, power: $20 \mathrm{~mW}$ ) excluded an oxygen from the reactor. 
Further, the ion-sensitive PSX thin layers were deposited by spin coating and patterned by ultraviolet photolithography techniques [6]. The mixture for ion-sensitive and photosensitive polymer contained in mass: $97.4 \%$ of polysiloxane RMS- $033,1 \%$ of nonactine as ammonium ionophore, $1 \%$ of DMPA and $0.6 \%$ of lipophilic salt KTFBP. The membranes components were dissolved into THF in a $2 / 1$ dilution ratio. After a MTPS/toluene silanisation step at $80^{\circ} \mathrm{C}$ during 10 minutes to promote an adherence with the silicon substrate, the PSX-based solution was deposited by spin-coating using a SUSS GYRSET RC-8 spin coater. Then, after the THF solvent evaporation under nitrogen atmosphere, ultraviolet (UV) exposure was performed under a non-oxidising ambient using a Karl Suss MA-6 contact alignment system. Finally, the PSX patterns (thickness around 30 microns) were obtained using xylene as developer (figure 4). Ultraviolet diffraction phenomena are still responsible for the fabrication of badly defined PSX layers and the whole spin-coating and photolithography process has still to be improved. Nevertheless, these technological results show the feasibility of mass-fabricated PSX-based pNH4-ISFETs.

Finally, the $5 \times 5 \mathrm{~mm}^{2}$ FSC-pNH4-ISFETs chips were reported on 9 x $9 \mathrm{~mm}^{2}$, back-sideconnected printed circuit boards (BSC-PCB). After gold wedge wire bonding, they were encapsulated using two epoxy resins (H70E-4 and H70E-2 purchased from Epoxy Technology) with different values of viscosity. This two-step dispense process was developed to leave the $\mathrm{SiO}_{2} / \mathrm{Si}_{3} \mathrm{~N}_{4} / \mathrm{PSX}$ ion-sensitive gate uncovered. The electrical connexions of FSC-pNH $4-I S F E T s$ have been taken on the back-side of PCB. The whole ChemFET microsensor, i.e. the FSC$\mathrm{pNH}_{4}$-ISFET/BSC-PCB, was studied in order to be compatible with developed the flow-cell concept (figure 2).

A specific characterization stand was finally developed in order to evaluate the sensitivity and selectivity of sensors in real time. It regroups different fluidic equipments (liquid distribution system, cooling/heating stirrer, peristaltic pump, liquid flow controller, pneumatic valves), the flow-analysis cell (including the specific flow-through head and the reference 
electrode to apply the gate-source voltage $\mathrm{V}_{\mathrm{GS}}$ to the studied solution) and a ChemFET measurement interface. All the characterization system was monitored by a personal computer for data acquisition and control. Finally, after keeping the pNH4-ISFET microsensors in a conditional $\mathrm{NH}_{4} \mathrm{NO}_{3}\left(10^{-1} \mathrm{M}\right)$ solution for a day, their detection capacities were studied for various ammonium-based solutions $\left(1 \leq \mathrm{pNH}_{4} \leq 5\right)$. All the measurements were carried out at room temperature and standard illumination.

\section{Results and discussion}

Firstly, the behaviour of $\mathrm{pNH}_{4}$ microsensors have been studied in various $\mathrm{pH}$ solutions in order to valid a good membrane's proprieties. If quasi-nernstian $\mathrm{pH}$ sensitivity was evidenced for the former $\mathrm{pH}-\mathrm{ISFETs}$, no $\mathrm{pH}$ sensitivity has been found for the $\mathrm{pNH}_{4}$-ISFETs whatever the PSX-based ion-sensitive layers deposition techniques.

Then, the detection $\mathrm{NH}_{4}{ }^{+}$ions have been studied using the ISFET microsensor. This one was operating in the standard current-voltage saturation mode $\left(\mathrm{I}_{\mathrm{ds}}=0.1 \mathrm{~mA}, \mathrm{~V}_{\mathrm{ds}}=1 \mathrm{~V}\right)$. Figure 5 shows a typical response obtained for the manually dispensed ion-sensitive, polysiloxane layers. Even if saturation phenomena are evidenced for the lowest concentrations $\mathrm{pNH}_{4} \approx 5$, good sensitivity, i.e. around $47 \mathrm{mV} / \mathrm{pNH}_{4}$, has been shown on ammonium ion concentration ranges appropriate with the water analysis $\left(1 \leq \mathrm{pNH}_{4} \leq 4\right)$. Nevertheless, different drawbacks of this deposition technique have been highlighted. First, it is responsible for positioning problems of the PSX ion-sensitive layers onto the $\mathrm{SiO}_{2} / \mathrm{Si}_{3} \mathrm{~N}_{4}$ gate. Second, it is characterised by the non-reproducibility of the deposited PSX droplets (size and geometry), preventing from obtaining an industrial fabrication process for the $\mathrm{pNH}_{4}$-ISFETs.

As a result, the mass-fabrication process using spin-coating and ultraviolet photolithography techniques has been developed. By analogy with the previous study, the $\mathrm{pNH}_{4}-\mathrm{ISFET}$ sensors have still been characterized in the $\mathrm{I}-\mathrm{V}$ saturation mode $\left(\mathrm{I}_{\mathrm{ds}}=0.2 \mathrm{~mA}, \mathrm{~V}_{\mathrm{ds}}\right.$ $=3 \mathrm{~V})$. Functioning modes of two ISFETs is not the same that is explained by relatively 
important thickness of spin-coated layers. Typical results obtained for the spin-coated, ionsensitive polysiloxane layers are shown in figure 6. Again, average sensitivity around $47 \mathrm{mV} / \mathrm{pNH}_{4}$ has been evidenced on the $[1-4] \mathrm{pNH}_{4}$ range. A high value of membrane resistance is responsible for a little output voltage oscillations on the both curves [11].

If the two processes developed for the PSX ion-sensitive layers fabrication have finally given similar $\mathrm{NH}_{4}^{+}$ion sensitivity with similar selectivity factors $(\log \mathrm{K})$ for sodium and potassium ions (-2.08 end -2.02 respectively), they have been compared in order to understand the influence of the polysiloxane layers on the ISFET electrical behaviour (figure 7). The increase of the PSX thickness from 10 microns for the manually deposed layers to 30 microns for the spin-coated layers have been found to be responsible for an increase of the ISFET threshold voltage $\mathrm{V}_{\text {T }}$ to $2 \mathrm{~V}$ as well as a decrease of the ISFET bias current. Such phenomena should be related to the insulating characteristics of the polysiloxane layers and more precisely to the decrease of the total gate capacitance PSX/Si3 $\mathrm{N}_{4} / \mathrm{SiO}_{2}$.

\section{Conclusion}

$\mathrm{SiO}_{2} / \mathrm{Si}_{3} \mathrm{~N}_{4}$ front-side connected ChemFET chips have been fabricated and reported on back-side connected printed circuit board to fit to the water analysis specifications. They have been adapted to the ammonium $\mathrm{NH}_{4}{ }^{+}$ion detection thanks to polysiloxane-based (PSX) ionsensitive membranes deposited on top of the dielectric gate either by micropipette, either by spin-coating and photolithography techniques. Whatever the deposition techniques, good detection sensitivities, i.e. around $47 \mathrm{mV} / \mathrm{pNH}_{4}$, have been evidenced on appropriate concentration ranges $\left(1 \leq \mathrm{pNH}_{4} \leq 5\right)$. Nevertheless, the manually deposed layers have been characterised by non-reproducibility while the thicker spin-coated layers have been responsible for an increase of the ISFET threshold voltage and a decrease of the ISFET bias current.

These works will be continued by studying the deposition of polysiloxane layers thanks to spin coating and photolithography techniques. The whole technological process has to be 
improved in order to decrease the thickness of the PSX membrane while decreasing the influences of UV diffraction phenomena. So, by mass-fabricating ion-sensitive layers from an industrial point of view, $\mathrm{pNH}_{4}$-ISFETs microsensors will be developed for the monitoring of environmental pollution and more precisely for ground water analysis.

\section{Acknowledgements}

This work was supported by the European FP5 project SEWING (contract $n^{\circ}$ IST-200020084)

\section{References}

[1] P. Bergveld, "Thirty years of ISFETOLOGY What happened in the past 30 years and what may happen in the next 30 years", Sensors and Actuators, B88 (2003), 1-20.

[2] N. V. Kolytcheva, Helmut Müller, Jens Marstalerz, "Influence of the organic matrix on the properties of membrane coated ion sensor field-effect transistors", Sensors and Actuators B: $58,(1999), 456-463$.

[3] P Temple-Boyer, J. Launay, I. Humenyuk, T. Do Conto, A. Martinez, C. Bériet, A. Grisel, "Study of front-side connected chemical field effect transistors for water analysis", Microelectronics Reliability, 44 (2003), 443-447.

[4] J. Muñoz, C. Jimenez, A. Bratov, J. Bartroli, S. Alegret, C. Dominguez, "Photosensitive polyurethanes applied to the development of CHEMFET and ENFET devices for biomedical sensing" , Biosensors \& Bioelectronics 12 (1997) 577-585.

[5] P.D. Van der Wal, A. Van den Berg, N.F. de Rooij, "Universal approach for the fabrication of $\mathrm{Ca}^{2+}, \mathrm{K}^{+}$and $\mathrm{NO}_{3}{ }^{-}$sensitive membrane ISFETs", Sensors and Actuators, $\mathrm{B}, 18-19$ (1994), 200-207.

[6] A. Van den Berg, A. Grisel, "An ISFET-based calcium sensor using a photopolymerized polysiloxane membrane", Sensors and Actuators, B4 (1991), 235-238. 
[7] D.N. Reinhoudt, "Durable chemical sensors based on field-effect transistors", Sensors and Actuators B 24, (1995), 197-200.

[8] C. Cané, I. Gràcia and A. Merlos, "Microtechnologies for pH ISFET chemical sensors", Microelectronics Journal, 28 (1997), 389-405.

[9] M. Chudy, W. Wroblewski, A. Dybko, Z. Brzozka, "Multi-ion analysis on versatile sensor head", Sensors and Actuators, B78 (2001), 320-325.

[10] W. Wróblewski, M. Chudy, A. Dybko Z. Brzózka, "NH4${ }^{+}$-sensitive chemically modified field effect transistors based on siloxane membranes for flow-cell applications", Analytica Chimica Acta, 401 (1999), 105-110.

[11] A. Bratov, N. Abramova, C. Domínguez, "Investigation of chloride sensitive ISFETs with different membrane compositions suitable for medical applications", Analytica Chimica Acta, Vol. 514, (2004), 99-106.

\section{Biographies}

Iryna Humenyuk was born the 29th of July 1977. She received the degree in electronic engineering from the Lviv Polytechnic National University (Ukraine) in 2000 and her Diplome d'Etudes Approfondies in Microelectronics from the Institut National des Sciences Appliquées de Toulouse (France) in 2002. She joined the Laboratoire d'Architecture et d'Analyse des Systèmes from the French Centre National de la Recherche Scientifique (LAAS-CNRS) in 2002. She is preparing a $\mathrm{PhD}$ thesis on the development of chemical microsensors for water monitoring.

Benoît Torbiero was born the $4^{\text {th }}$ of February 1980 . He received his master in electronics degree from the Université Paul Sabatier de Toulouse (France) in 2002 and his Diplome d'Etudes Approfondies in Microelectronics from the Institut National Polytechnique de Toulouse (France) in 2003. He joined the Laboratoire d'Architecture et d'Analyse des Systèmes 
from the French Centre National de la Recherche Scientifique (LAAS-CNRS) in 2003. He is preparing a $\mathrm{PhD}$ thesis on the development of chemical microsensors for medical applications.

Sandrine Assié-Souleille was born the 15 September 1975. She joined the Laboratoire d'Architecture et d'Analyse des Systèmes from the French Centre National de la Recherche Scientifique (LAAS-CNRS) in 2002. She is working as an engineer in the field of instrumentation and characterisation.

René Colin was born the 1st of September 1964. He joined the Laboratoire d'Architecture et d'Analyse des Systèmes from the French Centre National de la Recherche Scientifique (LAASCNRS) in 2002. He is working as a technician in the field of packaging and is in charge of operations and developments for microelectronic components and microsystems.

Xavier Dollat was born the $24^{\text {th }}$ of December 1966 . He joined the Laboratoire d'Architecture et d'Analyse des Systèmes from the French Centre National de la Recherche Scientifique (LAASCNRS) as an technical engineer in 2001. He is responsible for the technological development of mechanical structures and elements applied systems and microsystems.

Bernard Franc was born the 12 November 1963. He joined the Laboratoire d'Architecture et d'Analyse des Systèmes from the French Centre National de la Recherche Scientifique (LAASCNRS) in 1983. He is working as an engineer in the field of software development.

Augustin Martinez was born the $24^{\text {th }}$ of May 1942. He joined the Laboratoire d'Architecture et d'Analyse des Systèmes from the French Centre National de la Recherche Scientifique (LAASCNRS) in 1966 and received his Doctorat d'Etat in Physics from the Université Paul Sabatier de Toulouse (France) in 1976. In 1980, he became Professor at the Institut National des Sciences Appliquées de Toulouse (France). He is working on the development of micro and nanotechnologies.

Pierre Temple-Boyer was born the $25^{\text {th }}$ of October 1966. He received the degree in electronic engineering from the Ecole Supérieure d'Electricite (Paris - France) in 1990. He joined the Laboratoire d'Architecture et d'Analyse des Systèmes from the French Centre National de la 
Recherche Scientifique (LAAS-CNRS) in 1992 and received the $\mathrm{PhD}$ degree from the Institut National des Sciences Appliquées de Toulouse (France) in 1995. Since then, as a senior researcher, he has been working on the development of microtechnologies for sensors applications. 


\section{FIGURE CAPTIONS}

Figure 1: Flow cell for ChemFET sensors

Figure 2: Characterization chamber

Figure 3: Photograph of the $5 \times 5 \mathrm{~mm}^{2} \mathrm{pH}-\mathrm{ChemFET} / \mathrm{ReMOS}$ silicon chip

Figure 4: mass-fabrication of the ionosensitive, polysiloxane-based layer on top of the $\mathrm{SiO}_{2} / \mathrm{Si}_{3} \underline{\mathrm{N}}_{4} \mathrm{pH}$-sensitive gate

Figure 5: response of the $\mathrm{pNH}_{4}$-ISFET with the dip-coated, ionosensitive polysiloxane layers

Figure 6: response of the $\mathrm{pNH}_{4}$-ISFET with the spin-coated, ionosensitive polysiloxane layers

Figure 7: Comparison of the $\mathrm{pNH}_{4} \underline{\text { responses for the two different } \mathrm{pNH}_{4-I S F E T s}}$ 


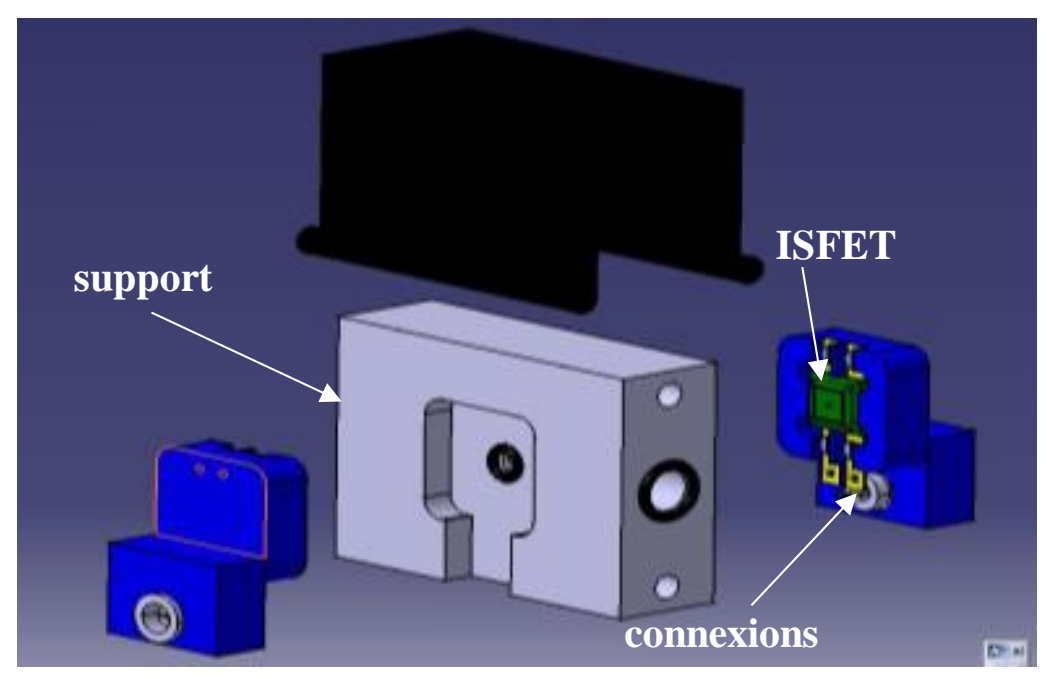

Figure 1: Flow cell for ChemFET sensors 


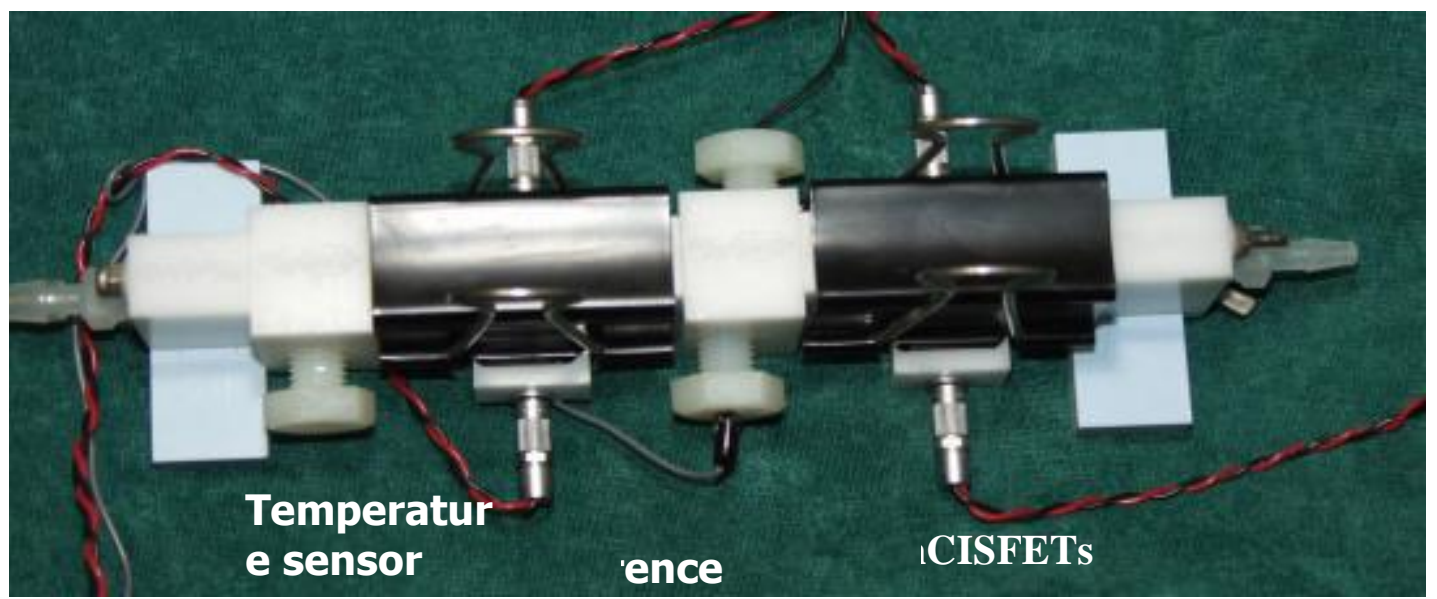

Figure 2: Characterization chamber 


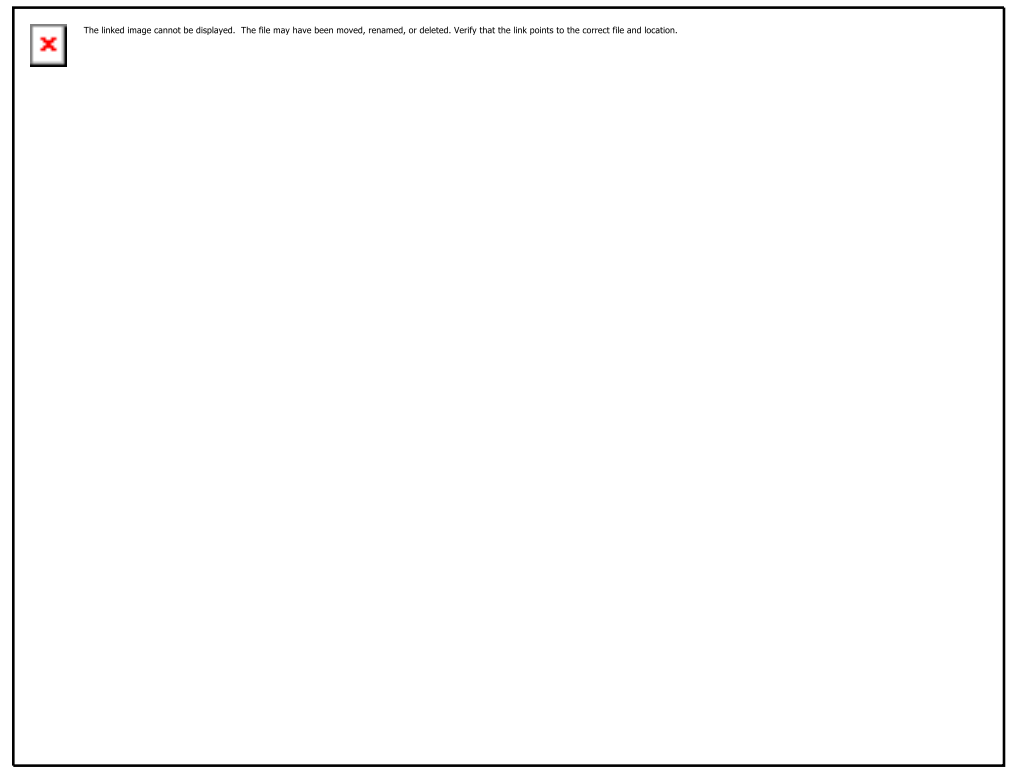

Figure 3: Photograph of the $5 \times 5 \mathrm{~mm}^{2} \mathrm{pH}-\mathrm{ChemFET} / \mathrm{ReMOS}$ silicon chip 


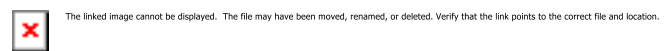

.

Figure 4: Mass-fabrication of the ion-sensitive, polysiloxane-based layer on top of the $\mathrm{SiO}_{2} / \mathrm{Si}_{3} \underline{N}_{4} \mathrm{pH}$-sensitive gate (pattern detail and profile) 


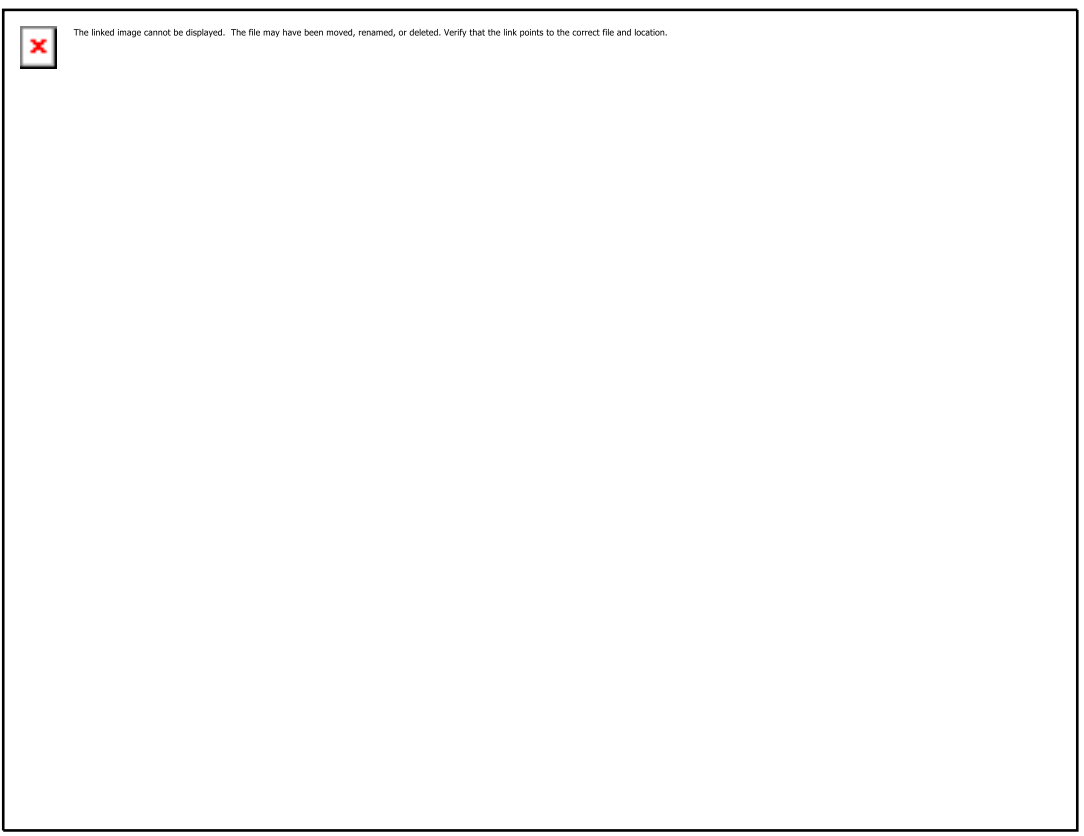

Figure 5: Responses of the $\mathrm{pNH}_{4}$-ISFET with the manually dispensed ion-sensitive polysiloxane layers 


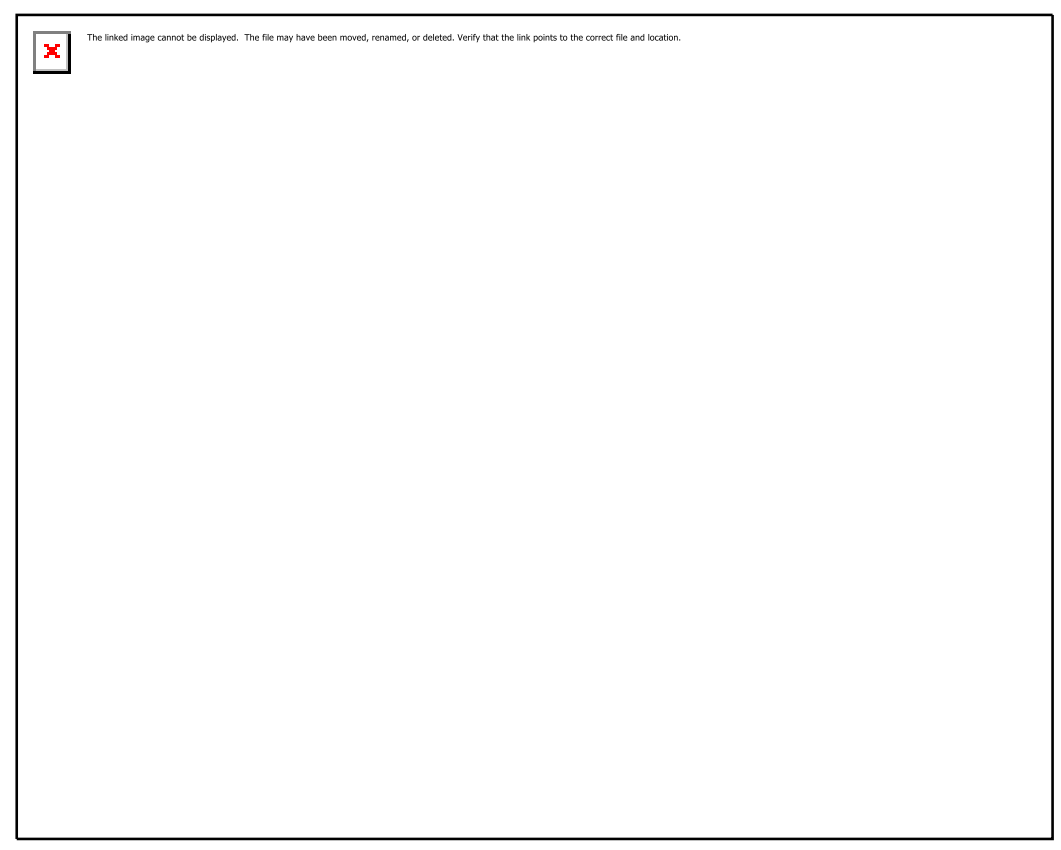

Figure 6: Responses of the $\mathrm{pNH}_{4}$-ISFET obtained with the spin-coated, ion-sensitive polysiloxane layers 


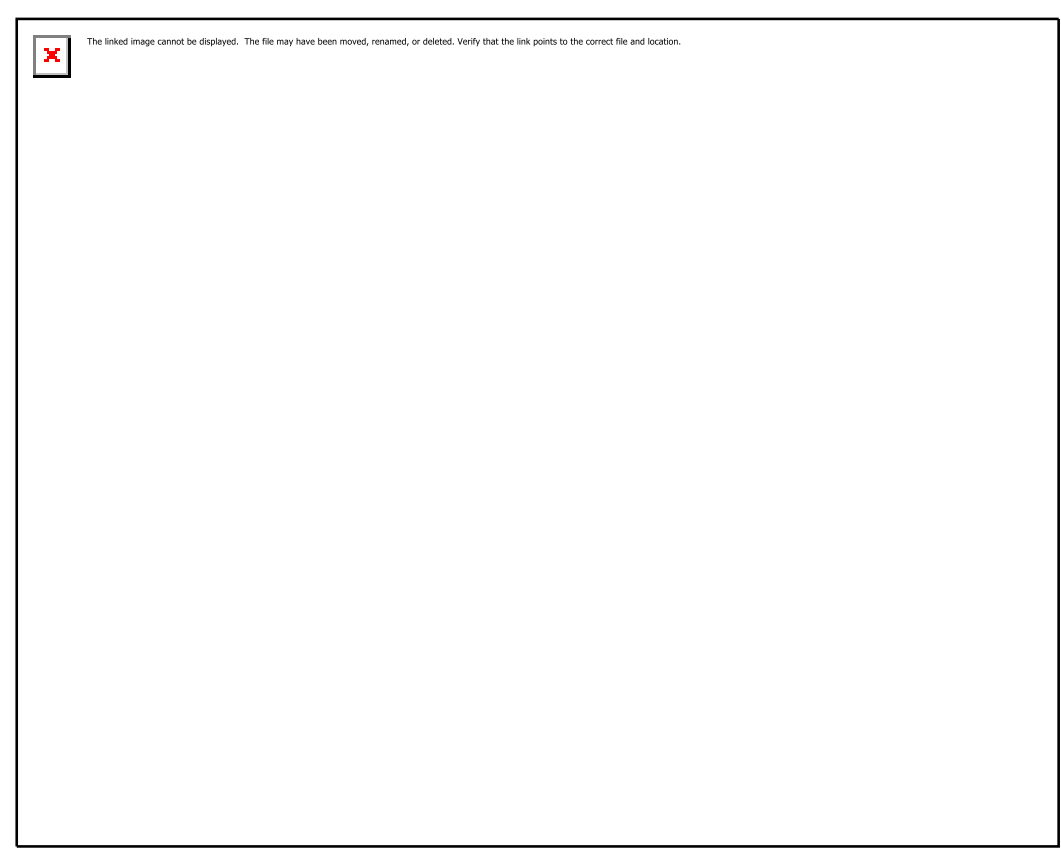

Figure 7: Comparison of the $\mathrm{pNH}_{4} \underline{\text { responses for the two different } \mathrm{pNH}} 4$-ISFETs 